\title{
Adenine Nucleotide Translocation in Liver Mitochondria of Hypothyroid Rats ${ }^{1}$
}

\author{
FREDERIC L. HOCH \\ Departments of Internal Medicine and Biological Chemistry, The University of Michigan, 7696 Kresge \\ Building, Ann Arbor, Michigan 48109
}

Received June 6, 1976

\begin{abstract}
In measurements using a disc filtration method, liver mitochondria obtained from hyputhyroid rats transluciate external $A D P$ at $0^{\circ} \mathrm{C}$ via the atractyloside-sensitive carrier much more slowly than do mitochondria from normal rats, confirming the findings of Portnay et al. (Biochem. Biophys. Ries. Commun. 55, 17, 1973). The hypothyroid mitochondria contain $60 \%$ more ATP + ADP than do mituchondria from normals, but the excess nucleotides are not exchangeable and so do not contribute to translocation. A decrease in the first-order rate constant accounts for the decreased velocity. Neither a decrease in the number of translocator sites nor changes in ADP phosphorylation or ATPase activity seem to account for the abnormal kinetics of translocation. Although the filtration method limits the maximal translocation rate observed in normal mitochondria at temperatures above $17^{\circ} \mathrm{C}$ that induce a fluid membrane state, no such transition is seen in mitochondria from hypothyroid rats up to $35^{\circ} \mathrm{C}$, indicating that the translocator is in an altered environment in hypothyroidism. Injecting a hypothyroid rat once with L-thyroxine corrects the abnormal compartmentation and produces a temperature-rate relationship like that in normal mitochondria in 3 days, a period which would accommodate the hormone actions reported on translation, membrane phospholipid synthesis, or fatty acid desaturation.
\end{abstract}

At $2^{\circ} \mathrm{C}$, the carrier-mediated atractyloside-sensitive uptake of ADP by intact mitochondria obtained from the livers of hypothyroid rats (hereafter referred to as $\mathrm{H}$ mitochondria) ${ }^{2}$ proceeds at about half the initial rate seen in mitochondria from normal rats ( $\mathbf{N}$ mitochondria); the administration of six daily injections of $0.2 \mu \mathrm{g}$ of $\mathrm{L}^{-}$ thyroxine $\left(\mathrm{LT}_{4}\right)$ per gram body weight to hypothyroid rats restores the rate to normal levels (1). It was proposed that thyroid hormone controls $\mathrm{O}_{2}$ consumption by stimulating adenine nucleotide translocation. The amount and the phosphorylation state of the endogenous ATP + ADP, as well as the rate constant of the translocator, control ADP translocation in the liver mito-

1 This work was supported in part by grants from the National Science Foundation (GB-42256) and The University of Michigan Horace H. Rackham School of Graduate Studies.

${ }_{2}^{2}$ Abbreviations used: $\mathrm{LT}_{4}$, L-thyroxine; $\mathrm{H}$, hypothyroid; N, normal; SDS, sodium dodecyl sulfate. chondria of normal rats (2-4). To determine the mechanisms involved in the hormonal effects, we have examined endogenous adenine nucleotides, the kinetics and temperature dependence of ADP translocation, and the effects of oxidative phosphorylation thereon in mitochondria from the livers of normal, hypothyroid, and $\mathrm{LT}_{4}$-injected hypothyroid rats. A disc filtration method was used to separate the mitochondria from external labeled ADP, as in (1). Preliminary reports have been made on these studies $(5,6)$.

\section{MATERIALS AND METHODS}

Normal male rats (Spartan, Haslett, Michigan) were maintained on Tekland Mills Mouse \& Rat Diet and thyroidectomized male rats from the same source were fed a low-iodine diet (Nutritional Biochemicals, Inc., Cleveland, Ohio). To determine whether the difference in the diets contributes to changes observed in the mitochondrial adenine nucleotide carrier, six normal rats were fed the lowiodine diet supplemented with $0.0005 \% \mathrm{KI}$ in their 
drinking water for at least 1 month; adenine nucleotide carrier activity was unchanged. However, the cost precluded the routine use of the low-iodine diet for the normal rats, although such a diet is necessary to prevent the hypothyroid rats from receiving significant amounts of hormone (7). The thyroidectomized rats, weighing 50-75 g, were injected intraperitoneally with $0.25 \mathrm{mCi}$ of ${ }^{131} \mathrm{I}$ as $\mathrm{NaI}$ within a few days after surgery and were used at least 3 weeks later. Hypothyroid rats were injected intraperitoneally with varying doses of $\mathrm{LT}_{\mathbf{4}}$ per gram body weight and killed $30 \mathrm{~min}$ to 3 days later. The hormone, obtained as L-thyroxine pentahydrate (Sigma Chemicals, St. Louis, Missouri), was dissolved in fresh $0.01 \mathrm{~N} \mathrm{NaOH}$ just before each injection; control hypothyroid rats were injected with equivalent volumes of $0.01 \mathrm{~N} \mathrm{NaOH}$.

Male rats that had been fasted 18-24 $h$ were decapitated, and mitochondria were prepared from their livers in $0.25 \mathrm{~m}$ sucrose (8). Two hypothyroid animals or one normal were killed to obtain equivalent amounts of liver homogenate. Mitochondria were washed and suspended in $0.25 \mathrm{M}$ sucrose, and volumes were adjusted to give a final concentration of 3 or $15 \mathrm{mg}$ of protein $/ \mathrm{ml}$. Protein was estimated by a rapid biuret method (9) using bovine serum albu$\mathrm{min}$ as a reference. The ratio of mitochondrial cytochrome $a$ :protein was constant in all the thyroid states studied.

Reagents of analytical or comparable grade were obtained commercially. Water was double distilled. For measuring the kinetics of ADP translocation (10), the 2.0-ml reaction mixture contained $2 \mathrm{mM}$ EDTA; $1 \mathrm{~mm}$ adenosine 3 '-phosphate; $0.25 \mathrm{M}$ sucrose; $20 \mu \mathrm{M}\left[{ }^{14} \mathrm{C}\right] \mathrm{ADP}$, approximately $120 \mathrm{cpm} / \mathrm{nmol}$; and $10 \mathrm{~mm}$ triethanolamine at $\mathrm{pH}$ 7.0. The uptake of labeled ADP was started by addition of $0.1 \mathrm{ml}$ of a suspension of mitochondria in $0.25 \mathrm{M}$ sucrose, containing 3.0 or $15 \mathrm{mg}$ of protein $/ \mathrm{ml}$. The temperature of the reaction mixtures was held constant within $0.1^{\circ}$ in a heated and refrigerated water bath. Three different samples were incubated according to (10): (a) contained $10 \mu \mathrm{M}$ potassium atractyloside from $t$ $=0$; (b) received $10 \mu \mathrm{M}$ atractyloside at the indicated time $t$; and (c) contained no atractyloside. At time $t$ for samples (a) and (c) and at time $t+1 \mathrm{~min}$ for (b) the mixtures were rapidly filtered through a chilled Millipore disc (AAWP 02400; pore size, $0.8 \mu \mathrm{m}$ ) on a coarse-sintered disc under suction $(1,11)$. Using a syringe and needle to deliver the reaction mixture, it was possible to get reproducible results with incubations as short as 5 and $10 \mathrm{~s}$. The retained mitochondria were washed with ice-cold $0.25 \mathrm{~m}$ sucrose. The filter disc was then dried in a scintillation vial and counted in $10 \mathrm{ml}$ of scintillation fluid. The ADP taken up was measured from the known specific radioactivity, and the atractyloside-sensitive binding and exchange were determined according to (10). Atractyloside-insensitive binding was usually less than $10 \%$ of the total uptake at $0^{\circ} \mathrm{C}$.
The translocation in $\mathrm{N}$ mitochondria is a compulsory exchange been internal and external ATP and ADP. The translocation activity, $v_{\mathrm{T}}$, should depend on both $k_{\mathrm{T}}$, a first-order reaction constant, and $\mathrm{Ai}_{\mathrm{E}}$, the concentration of the internal exchangeable ATP + ADP under conditions of excess external nucleotide concentration (12):

$$
v_{\mathrm{T}}=k_{\mathrm{T}} \mathrm{Ai}_{\mathrm{E}} \text {. }
$$

The value for $\mathrm{Ai}_{\mathbf{E}}$ was determined from the atractyloside-sensitive exchange of external labeled ADP when equilibrium was reached and was used to calculate $k_{\mathrm{T}}$ from measurements of the initial rates of exchange. When $\mathrm{Ai}$, the amount of external ADP exchanged at time $t$, is measured in normal rat liver mitochondria the initial exchange is first order, and

$$
k_{\mathrm{T}}=-\ln \left(1-\mathrm{Ai} / \mathrm{Ai}_{\mathrm{E}}\right) / t
$$

according to (12).

The $V$ of translocation and the apparent $K_{m}$ for external ADP were calculated from values of $\left(v_{\mathrm{r}}\right)^{-1}$ as a function of $[\mathrm{ADP}]^{-1}$. At $0^{\circ} \mathrm{C}$, the external [ADP] was between 0.57 and $20 \mu \mathrm{M}$. Rate constants at temperatures up to $35^{\circ} \mathrm{C}$ were derived from rates measured at three ADP concentrations, 0.8, 1.33, and $20 \mu \mathrm{M}$, using $0.3 \mathrm{mg}$ of mitochondrial protein. The calculation of $k_{\mathrm{T}}$ from extrapolated values for the $V$ of translocation thus minimized the technical difficulties of measuring the rate constants at high temperatures, since the actual rates, especially at the two lower concentrations, were slow enough to measure reproducibly even at $35^{\circ} \mathrm{C}$. 'The effects of temperature on $k_{\mathrm{T}}$ were plotted as $\log k_{\mathrm{T}}$ vs $\left[K^{\circ}\right]^{-1}$, the Arrhenius plot (13). A single freshly prepared batch of mitochondria provided an insufficient quantity for measuring the $V$ at eight different temperatures. Accordingly, one batch of mitochondria was used at each temperature. To compare the results, $k_{\mathrm{T}}$ at $0^{\circ} \mathrm{C}$ in the presence of $20 \mu \mathrm{M}$ ADP was measured in each batch as an estimate of the amount of translator: in six preparations of $\mathrm{H}$ mitochondria, $k_{\mathrm{T}}=1.64 \pm 0.14(\mathrm{SE}) \mathrm{min}^{-1}$, and in seven preparations of $\mathrm{H}$ mitochondria, $k_{\mathrm{T}}=0.47 \pm 0.04$ $\mathrm{min}^{-1}$. These means were used to normalize the $\boldsymbol{k}_{\mathrm{T}}$ values obtained from $V$ measurements.

In mitochondria from normal rats, $\mathrm{Ai}_{\mathrm{E}}=\mathrm{Ai}_{\mathrm{T}}$, the total endogenous ATP + ADP (12), although others have found that $A_{\mathrm{E}}<A \mathrm{i}_{\mathrm{T}}(14,15)$. To determine the extent of exchangeability $\mathrm{Ai}_{\mathrm{E}} / \mathrm{Ai}_{\mathrm{T}}$, and the phosphorylated state of the endogenous exchangeable adenine nucleotides $(100 \times$ ATP)/ATP + ADP), internal mitochondrial adenine nucleotides were measured. Either freshly suspended mitochondria, or mitochondria incubated and filtered as in the translocation assay above except that no radioactive ADP was present, were examined. A $0.1-\mathrm{ml}$ aliquot of a mitochondrial suspension containing $15 \mathrm{mg}$ of protein/ $\mathrm{ml}$, or the washed disc retaining a similar aliquot of mitochondria after incubation, was extracted overnight in $0.5 \mathrm{M}$ perchloric acid at $4^{\circ} \mathrm{C}$. The extracts 
were neutralized and perchlorate salts were removed hy centrifugation. The ATP, ADP, and AMP in the extracts were then measured enzymatically $(16,17)$, and the assays were corrected for recovery from measurements of concomitantly processed samples of standard solutions.

\section{RESULTS}

\section{Adenine Nucleotide Contents}

Table $I$ shows that $A i_{T}$ is greater in the mitochondria from hypothyroid rats than in those from normal rats, by $44 \%$ when the mitochondria are freshly prepared and by $60 \%$ under the conditions of the translocation assay. The phosphorylation state in the $\mathrm{H}$ mitochondria is lower than in the normals, through an increase in endogenous ADP content. Liver mitochondria from normal rats contain $10.9 \mathrm{nmol}$ of ATP + ADP per milligram (12) and 10 to 17 nmol of ATP + ADP + AMP $(12,18)$, values somewhat higher than these in Table I.

One $\mathrm{LT}_{4}$ injection of $0.5 \mu \mathrm{g} / \mathrm{g}$ given to a hypothyroid rat 3 days before killing corrects the level of $\mathrm{Ai}_{\mathrm{T}}$, but does not change the phosphorylation state. The incubation and disc filtration involved in the translocation assay decrease mitochondrial $\mathbf{A i}_{\mathrm{T}}$ by $2.9 \%$ in the untreated hypothyroid rats, but consistently decrease $A i_{T}$ by $10-15 \%$ in both the pretreated hypothyroid and the normal rats and depress the phosphorylation state in all groups. Incubation of $\mathrm{N}$ mitochondria for $10 \mathrm{~min}$ at $25^{\circ} \mathrm{C}$ (not shown in Table $I$ ) does not decrease $\mathrm{Ai}_{\mathrm{T}}$ further, so the loss of nucleotides seems to be due to the filtration. Thyroid state does not affect endogenous AMP content, nor does incubation with external ADP, which is consistent with the observed exclusion of AMP from specific translocation (12).

Primack and Popovitch (19) did not observe any differences in adenine nucleotide contents in freshly isolated liver mitochondria from euthyroid and hypothyroid rats. Compared with our $\mathrm{N}$ mitochondria (Table I) their $\mathrm{N}$ mitochondria contained $23 \%$ less total adenine nucleotides and twice as much of that was AMP. Compared with our $\mathrm{H}$ mitochondria, their $\mathrm{H}$ mitochondria contained $44 \%$ less total nucleotides and three times as much was AMP. It is difficult to reconcile these results unless methodological, rat strain, or thyroid state differences are invoked.

\section{Approach to Equilibrium}

Figure 1 shows the time course of the atractyloside-sensitive exchange of external labeled $\mathrm{ADP}(=\mathrm{Ai})$ at $0^{\circ} \mathrm{C}$ and compares $\mathrm{Ai}$ with $\mathrm{Ai}_{\mathrm{T}}$. Normal mitochondria translocate ADP rapidly in the first min-

TABLE I

Endogenous Adenine Nucleotides in Liver Mitochondria from Rats of Different Thyroid States (nanomoles per milligram of protein $\pm \mathrm{SEM})^{a}$

\begin{tabular}{|c|c|c|c|c|c|c|}
\hline Mitochondria & $\begin{array}{l}\text { Treatment } \\
\text { in vitro }\end{array}$ & ATP & $A \cap P$ & AMP & $\begin{array}{c}\mathrm{Ai}_{\mathrm{T}} \\
\mathrm{ATP}+\mathrm{ADP}\end{array}$ & $\begin{array}{c}100 \times \mathrm{ATP} / \\
(\mathrm{ATP}+\mathrm{ADP})\end{array}$ \\
\hline Normal (8) & None & $6.1 \pm 0.6$ & $3.5 \pm 0.5$ & $2.4 \pm 1.1$ & $9.6 \pm 0.8$ & $63.5 \pm 4.7$ \\
\hline Hypothyroid (10) & & $6.9 \pm 0.6$ & $6.9 \pm 0.8^{* *}$ & $1.8 \perp 0.6$ & $13.8 \pm 0.9^{* *}$ & $50.7 \perp 3.7^{* * * *}$ \\
\hline $\begin{array}{l}\text { Hypothyroids }+\mathrm{LT}_{4} \\
0.5 \mu \mathrm{g} / \mathrm{g}+3 \text { days }(7)\end{array}$ & & $5.8 \pm 0.6$ & $5.1 \pm 0.2^{* * * *}$ & $2.6 \pm 0.8$ & $10.0 \pm 0.5^{* * *}$ & $52.6 \pm 3.4$ \\
\hline Normal (8) & $\begin{array}{l}2 \min \text { at } 0^{\circ} \mathrm{C} \\
\text { filtered }\end{array}$ & $3.6 \pm 0.4$ & $4.8 \pm 0.6$ & $1.5 \pm 0.7$ & $8.4 \pm 0.3$ & $42.8 \pm 6.2$ \\
\hline Hypothyroid (10) & & $4.6 \pm 0.4$ & $8.9 \pm 0.7^{* *}$ & $1.6 \pm 0.5$ & $13.4 \pm 0.8^{*}$ & $34.5 \pm 2.2$ \\
\hline $\begin{array}{l}\text { Hypothyroids }+\mathrm{LT}_{4} \\
\quad 0.5 \mu \mathrm{g} / \mathrm{g}+3 \text { days }(7)\end{array}$ & & $2.7 \pm 0.3^{* *}$ & $6.6 \pm 0.6^{* * * * *}$ & $2.9 \pm 0.9$ & $9.3 \pm 0.5^{\text {th }}$ & $29.6 \pm 3.5$ \\
\hline
\end{tabular}

Note. ${ }^{*}, P<0.001 ; * *, P<0.005$; *** $P<0.025$;***, $P<0.05$ : Hypothyroids vs normals, or $\mathrm{LT}_{4}$-injected hypothyroids vs hypothyroid controls.

a As described under Methods, mitochondria were prepared from the livers of normal or hypothyroid rats, or hypothyroid rats injected with $0.5 \mu \mathrm{g}$ of $\mathrm{LT}_{4} / \mathrm{g}$ and killed 3 days later. Either freshly prepared mitochondria, or mitochondria incubated with $\mathrm{ADP}$ at $0^{\circ} \mathrm{C}$ as in the assay for adenine nucleotide translocation and then filtered and washed, were extracted with perchloric acid; the extracts were enzymatically analyzed for adenine nucleotide contents, which are presented as nanomoles per milligram of mitochondrial protein. Means \pm SEM are shown, and the number of experiments appears in parentheses. The phosphorylation state of the endogenous ATP + ADP is calculated in the last column. 
ute and reach a steady state of exchange at about $6 \mathrm{~min}$, when $\mathbf{A i}=\mathrm{Ai}_{\mathrm{E}}=\mathrm{Ai}_{\mathrm{T}}$, as was found by (12). Hypothyroid mitochondria translocate ADP more slowly than $\mathrm{N}$ mitochondria in the first $2 \mathrm{~min}$ and reach a steady state of equilibrium only at 60-90 min, when $9.4 \mathrm{nmol}$ of ADP are taken up. The endogenous ATP + ADP maintains its high level throughout this period, and accordingly in $\mathrm{H}$ mitochondria, $\mathrm{Ai}_{\mathrm{E}}=0.7$ $A i_{T}$. The excess $A i_{T}$, which might contribute toward an increase in translocation velocity, is apparently not available for exchange, and the value for $\mathrm{Ai}_{\mathrm{E}}$ is not significantly changed in hypothyroidism.

The incomplete exchangeability of endogenous ATP + ADP in $\mathrm{H}$ mitochondria is almost fully corrected by pretreatment of hypothyroid rats with one dose of $0.5 \mu \mathrm{g}$ of $\mathrm{LT}_{4} / \mathrm{g} 3$ days before preparation of the mitochondria (not shown in Fig. 1). The early rapid exchange reaches about $40 \%$ of $\mathrm{Ai}_{\mathrm{T}}$ within $2 \mathrm{~min}$, and about $80 \%$ in 30 min.

The degree of exchangeability and the approach to equilibrium were also studied at temperatures up to $35^{\circ} \mathrm{C}$. At 5 and $8^{\circ} \mathrm{C}$, $\mathrm{H}$ mitochondria showed the biphasic progress seen at $0^{\circ} \mathrm{C}$. Although the initial phase of uptake was more rapid and complete, a second slower phase lasted up to

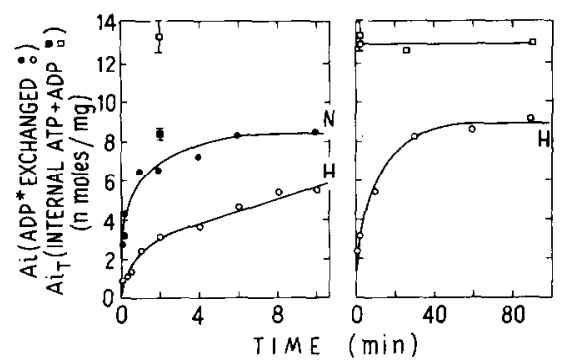

FIG. 1. Time course of the atractyloside-sensitive exchange of external labeled $\operatorname{ADP}\left(\mathrm{ADP}^{*}\right)$ at $0^{\circ} \mathrm{C}$ and its correlation with internal ATP + ADP concentrations, in liver mitochondria from normal (⿶, $\mathrm{N})$ and hypothyroid $(\mathrm{O}, \mathrm{H})$ rats. The specific exchange of $\mathrm{ADP}^{*}$ was measured as described in Methods, and $\mathrm{Ai}=$ nanomoles of ADP exchanged per milligram of mitochondrial protein is shown as a function of time of incubation. The values for $\mathrm{Ai}_{\mathrm{T}}=$ total internal ATP + ADP are shown as means \pm SEM for $\mathrm{N}(\boldsymbol{\square})$ and $\mathrm{H}(\square)$ mitochondria after $2 \mathrm{~min}$ of incubation and are taken from Table $\mathrm{I}$; values for $\mathrm{Ai}_{\mathrm{T}}$ for $\mathrm{H}$ mitochondria after incubation for up to 90 min are also shown on the right. the 15 -min point at $5^{\circ} \mathrm{C}$ and the 10 -min point at $8^{\circ} \mathrm{C}$. At temperatures above $16^{\circ} \mathrm{C}$ the slow second phase was not recognizable. The equilibrium values for the exchange $\left(\mathrm{Ai}_{\mathrm{E}}\right)$, as shown in Fig. 2, are about the same over this temperature range as at $0^{\circ} \mathrm{C}$. The uptake levels off at between 60 and $65 \%$ of $\mathrm{Ai}_{\mathrm{T}}$ (about $8.8 \mathrm{nmol} / \mathrm{mg}$ ). The mitochondria from 3-day $\mathrm{LT}_{4}$-injected hypothyroid rats (HT in Fig. 2) behave similarly, but their uptake of ADP levels off at $6.9 \mathrm{nmol} / \mathrm{mg}$. At the higher temperatures, the atractyloside-sensitive uptake by the mitochondria obtained from normal, hypothyroid, or hormone-treated hypothyroid rats decreases after 2 to 5 min of translocation, owing to a progressive increase in the atractyloside-insensitive binding, which is very low $(0.1$ to $0.2 \mathrm{nmol} / \mathrm{mg})$ at $0^{\circ} \mathrm{C}$ and up to the first $30 \mathrm{~s}$ of translocation. At temperatures above $8^{\circ} \mathrm{C}$ it increases 10 -fold after about $30 \mathrm{~min}$ at the expense of the atractyloside-sensitive uptake. This thermal inactivation of the specific adenine nucleotide translocator is not altered by the thyroid state, and it was assumed that it was too slow to affect the measurements of the initial rates of exchange, made as they were at 5 to $20 \mathrm{~s}$ after starting the reaction (see below).

\section{Extent of Early (2-min) Exchangeability}

The difference between the degree of specific labeling of internal ATP + ADP

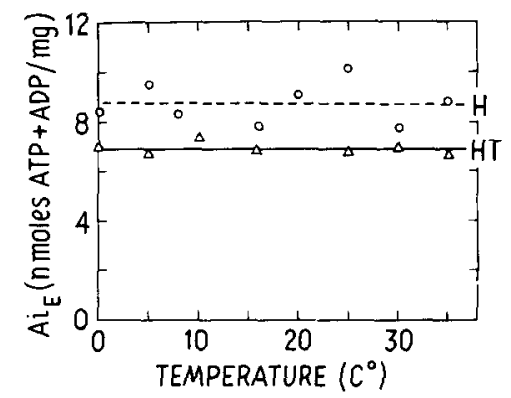

Fig. 2. The effect of temperature of incubation on $\mathrm{Ai}_{\mathrm{E}}$, the amount of endogenous ATP + ADP exchanged when equilibrium is reached. Mitochondria from hypothyroid rats $(\mathrm{O}, \mathrm{H})$ or from hypothyroid rats that had been pretreated with one injection of $\mathrm{LT}_{4}$ as in Table I $(\triangle, \mathrm{HT})$ were incubated as in Fig. 1 at the temperatures indicated. Incubation over this temperature range did not change the value for $\mathrm{Ai}_{\mathrm{E}}$ in $\mathrm{N}$ mitochondria. 
by $\mathrm{H}$ and $\mathrm{N}$ mitochondria at $0^{\circ} \mathrm{C}$ is maximal at about $2 \mathrm{~min}$ (Fig. 1). The effects of dose and duration of treatment of hypothyroid rats with $\mathrm{LT}_{4}$ on the specific binding and exchange of external ADP were therefore examined using this difference as a criterion. Measurements were also made at $25^{\circ} \mathrm{C}$ (Table II). Mitochondria from a hypothyroid rat are distinguished from normal mitochondria by a $39 \%$ decrease in ADP exchanged at $0^{\circ} \mathrm{C}$ and a $97 \%$ higher ratio of $\mathrm{ADP}$ exchanged at $25^{\circ} \mathrm{C}$ compared with $0^{\circ} \mathrm{C}$. When a hypothyroid rat is pretreated for $30 \mathrm{~min}$, neither the administration of an amount of $\mathrm{LT}_{4}$ that maintains the metabolic rate at normal levels when given daily to a thyroidectomized rat [10 $\mathrm{ng} / \mathrm{g},(20)]$ nor a much larger dose $(2.5 \mu \mathrm{g} /$ g) increases the $2-\min 0^{\circ} \mathrm{C}$ exchange or decreases the $25^{\circ} \mathrm{C}: \mathrm{O}^{\circ} \mathrm{C}$ exchange ratio. The smaller dose increases mitochondrial hormone content about 1.7-fold (21) and the larger almost 400-fold (22) within this period. Three days after injection, a dose of $0.5 \mu \mathrm{g}$ of $\mathrm{LT}_{4} / \mathrm{g}$, corresponding to that used by Tata (23) to avoid unphysiological effects and to define the time course of the stimulation of hepatocyte transcription, translation, and membrane synthesis (24, 25 ), corrects both the low $0^{\circ} \mathrm{C} 2$-min exchangeability and the high $25^{\circ} \mathrm{C}: 0^{\circ} \mathrm{C}$ exchange ratio.

The specific binding of external ADP is consistently less at 25 than at $0^{\circ} \mathrm{C}$. To test for an irreversible "damaging" effect of increased temperature on ADP exchangeability, $\mathrm{H}$ mitochondria were incubated in $0.25 \mathrm{M}$ sucrose at $25^{\circ} \mathrm{C}$ for $5 \mathrm{~min}$, then assayed for ADP exchange at 0 and $25^{\circ} \mathrm{C}$ (not shown in Table II). The prior incubation at $25^{\circ} \mathrm{C}$ did not alter the 2-min exchange at either temperature, and therefore, seems reversible in its effect.

\section{Initial Rates of Exchange}

With values for $\mathrm{Ai}_{\mathrm{E}}$ determined in the various thyroid states (Fig. 1), and assuming that $\mathrm{Ai}_{\mathrm{E}}$ is the same at 5-25 $\mathrm{s}$ as it is at equilibrium, initial rates of exchange were measured from exchanged radioactive $\mathrm{ADP}$ at 5-25 s at $0^{\circ} \mathrm{C}$ and Eq. [2], to obtain values for $k_{\mathrm{T}}$. Figure 3 shows that a plot of $-\ln \left(1-\mathrm{Ai} / \mathrm{Ai}_{\mathrm{E}}\right)$ versus $t$ is linear up to $30 \mathrm{~s}$ with cither $\mathrm{N}$ or $\mathrm{H}$ mitochondria. In the $\mathrm{H}$ mitochondria, a much slower exchange progresses after about $2 \mathrm{~min}$. The first-

TABLE II

Effects of Hypothyroidism and Pretreatment of Hypothyroid Rats with LT 4 on the AtractylosideSensitive 2-min UPtake of ADP at 0 and $25^{\circ} \mathrm{C}^{a}$

\begin{tabular}{|c|c|c|c|c|c|}
\hline \multirow[t]{2}{*}{ Source of mitochondria } & \multirow[t]{2}{*}{$N$} & \multirow{2}{*}{$\begin{array}{l}\text { Assay } \\
T\left({ }^{\circ} \mathrm{C}\right)\end{array}$} & \multicolumn{2}{|c|}{ Nanomoles per milligram } & \multirow{2}{*}{$\begin{array}{c}\text { Ratio } \\
25^{\circ} \mathrm{C}: 0^{\circ} \mathrm{C} \\
\text { exchanged }\end{array}$} \\
\hline & & & Bound & Exchanged & \\
\hline \multirow{2}{*}{ Normals } & 8 & 0 & $0.43 \pm 0.12$ & $4.60 \pm 0.35$ & \\
\hline & 7 & 25 & $0.27 \pm 0.12$ & $5.38 \perp 0.39$ & $1.16 \perp 0.04$ \\
\hline \multirow[t]{2}{*}{ Hypothyroids } & 20 & 0 & $0.70 \pm 0.12$ & $2.81 \pm 0.27^{*}$ & \\
\hline & 18 & 25 & $0.35 \pm 0.12$ & $5.93 \pm 0.23$ & $2.29 \pm 0.15^{*}$ \\
\hline \multirow[t]{2}{*}{ Hypothyroids $+10 \mathrm{ng}$ of $\mathrm{LT}_{4} / \mathrm{g} ; 30 \mathrm{~min}$} & 6 & 0 & $0.74 \pm 0.12$ & $2.30 \pm 0.20$ & \\
\hline & 6 & 25 & $0.39 \pm 0.20$ & $5.46 \pm 0.35$ & $2.44 \pm 0.16$ \\
\hline \multirow[t]{2}{*}{ Hypothyroids $+2.5 \mu \mathrm{g}$ of $\mathrm{LT}_{4} / \mathrm{g} ; 30 \mathrm{~min}$} & 7 & 0 & $1.52 \pm 0.39$ & $3.78 \pm 0.82$ & \\
\hline & 5 & 25 & $0.31 \pm 0.20$ & $6.40 \pm 0.62$ & $2.54 \pm 0.21$ \\
\hline \multirow[t]{2}{*}{ Hypothyroids $+10 \mathrm{ng}$ of $\mathrm{LT}_{4} / \mathrm{g} ; 3 \mathrm{~h}$} & 7 & 0 & $0.55 \pm 0.35$ & $2.85 \pm 0.35$ & \\
\hline & 7 & 25 & $0.39 \pm 0.16$ & $6.01 \pm 0.35$ & $2.20 \pm 0.16$ \\
\hline \multirow[t]{2}{*}{ Hypothyroids $+0.5 \mu \mathrm{g}$ of $\mathrm{LT}_{4} / \mathrm{g} ; 3$ days } & 6 & 0 & $0.42 \pm 0.13$ & $4.35 \pm 0.20^{* * *}$ & \\
\hline & 6 & 25 & $0.40 \pm 0.20$ & $4.86 \pm 0.25^{* * *}$ & $1.14 \pm 0.08^{* *}$ \\
\hline
\end{tabular}

Note. ${ }^{*}, P<0.001$ : vs $\mathrm{N}$ group comparison; ${ }^{* *}, P<0.001$; ${ }^{* * *}, P<0.005$ : vs $\mathrm{H}$ paired.

${ }^{a}$ Liver mitochondria were obtained from normal rats, hypothyroid rats, or hypothyroid rats injected once with $\mathrm{LT}_{4}$ in the dosage indicated and killed $30 \mathrm{~min}, 3 \mathrm{~h}$, or 3 days later. The mitochondria were incubated with labeled ADP as in Fig. 1, but for 2 min only, and at 0 and $25^{\circ} \mathrm{C}$; the nanomoles of nucleotide either specifically bound or specifically exchanged (see Methods) are shown as means \pm SEM. The ratios of ADP exchanged at $25^{\circ} \mathrm{C}$ to that exchanged at $0^{\circ} \mathrm{C}$, shown in the last column, were determined only in experiments in which a single batch of mitochondria was assayed at both temperatures, and so these ratios are not identical with the values calculated from the means exchanged, which include some assays performed only at $0^{\circ} \mathrm{C}$. 
order initial rate constant $k_{\mathrm{T}}=1.65 \mathrm{~min}^{-1}$ for normals and $0.51 \mathrm{~min}^{-1}$ for hypothyroids, and $v_{\mathrm{T}}=13.9$ and $4.8 \mathrm{nmol}$ ADP $\min ^{-1} \mathrm{mg}^{-1}$, respectively, a $66 \%$ decrease in hypothyroidism. These data are consistent with those of Portnay et al. (1) who found a $48 \%$ decrease in the rate of uptake at $2^{\circ} \mathrm{C}$ in hypothyroidism. However, our mitochondria from normal rats translocate $\mathrm{ADP}$ at $0^{\circ} \mathrm{C}$ two to six times faster than is reported by others using the same or different assay methods at $0-2^{\circ} \mathrm{C}(1,4,12)$.

Lineweaver-Burk plots and values for the $V$ of translocation and the apparent $K_{m}$ for external $\mathrm{ADP}$ at $0^{\circ} \mathrm{C}$ in normal and hypothyroid mitochondria are shown in Fig. 4. The $\mathrm{V}$ for $\mathrm{H}$ mitochondria is $27 \%$, and the $K_{m} 43 \%$, of the normal value. At

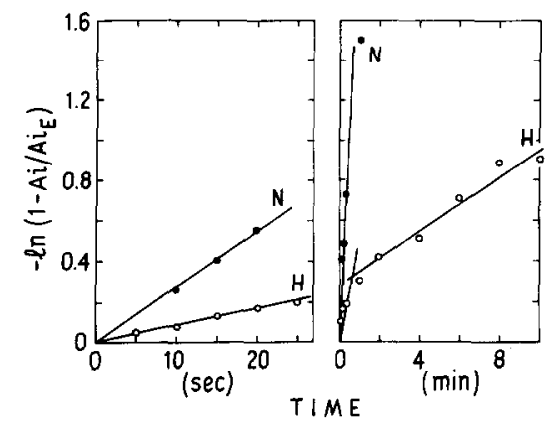

FIG. 3. Initial and subsequent rates of specific exchange of labeled $\mathrm{ADP}$ at $0^{\circ} \mathrm{C}$ by liver mitochondria from normal $(\boldsymbol{O}, \mathrm{N})$ or hypothyroid $(\mathrm{O}, \mathrm{H})$ rats. Mitochondria were incubated for the indicated times as in Fig. 1, and the exchange was calculated from the amount of ADP taken up and from $\mathrm{Ai}_{E}$ as described in Methods.

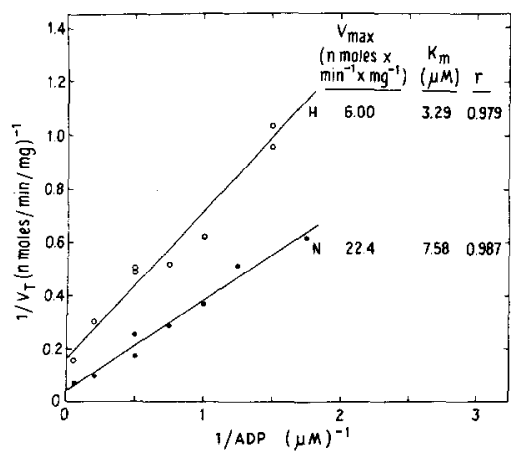

FIG. 4. Plots of reciprocal translocation velocity versus [ADP] for liver mitochondria from normal $(O, N)$ or hypothyroid $(\mathrm{O}, \mathrm{H})$ rats. Initial velocities were measured at $0^{\circ} \mathrm{C}$ as in Fig. 3. $0^{\circ} \mathrm{C}$, the $\mathrm{H}$ mitochondria thus translocate external ADP at a much slower maximal rate than $\mathrm{N}$ mitochondria, but they reach half-maximal translocation rate at about half the ADP concentration necessary in normals - perhaps a compensatory mechanism. Our value for $K_{m}$ in the mitochondria of normal rats is in the range reported by others [see (4)].

\section{Effects of Oxidative Phosphorylation}

The nonexchangeability of endogenous mitochondrial ATP + ADP is said to reflect "the establishment of a phosphorylation equilibrium between the ATP system and the energy transfer" (12). The incomplete exchangeability of endogenous ATP + ADP and the low rate constant of exchange in $\mathrm{H}$ mitochondria might therefore be caused by either an active phosphorylating system or an active ATPase. The fact that the phosphorylation state of the endogenous adenine nucleotides in $\mathrm{H}$ mitochondria is lower than in $\mathrm{N}$ mitochondria is consistent with an increased ATPase activity, but treatment of hypothyroid rats with $\mathrm{LT}_{4}$ does not improve the phosphorylation ratio although it increases the depressed exchangeability of the nucleotides (Table I). As is shown in Table III, blocking endogenous phosphorylation in hypothyroid mitochondria with $\mathrm{KCN}$ (3) or blocking both phosphorylation and ATPase action with oligomycin does not alter the translocation rate constant or the amount of labeled ADP exchanged at equilibrium. The translocation rate constant

\section{TABLE III}

Effects of Oxidative Phosphorylation on ADP EXChange at $0^{\circ} \mathrm{C}$ in MitochondRIA From HyPOTHYROID RATs ${ }^{a}$

\begin{tabular}{lcc}
\hline \multicolumn{1}{c}{ Agents added } & $\begin{array}{c}k_{\mathrm{T}} \\
\left(\mathrm{min}^{-1}\right)\end{array}$ & $\begin{array}{c}\text { ADP ex- } \\
\text { changed } \\
\text { at 90 min } \\
(\mathrm{nmol} / \mathrm{mg})\end{array}$ \\
\hline None & 0.36 & 7.4 \\
Succinate $(10 \mathrm{mM})+\mathrm{P}_{1}(10 \mathrm{mM})$ & 0.50 & \\
Oligomycin $(2 \mu \mathrm{g} / \mathrm{ml})$ & 0.44 & \\
KCN $(1 \mathrm{mM})$ & 0.37 & 7.8 \\
\hline
\end{tabular}

${ }^{a}$ The indicated agents were present at $t=0$, and either the rate constant $k_{\mathrm{T}}$ or the amount of labeled ADP exchanged at 90 min was measured, as in Figs. 3 and 1 , respectively. 
actually increases by almost $40 \%$ when oxidative phosphorylation is supported by the presence of succinate $+\mathrm{P}_{\mathrm{i}}$. There is therefore no evidence that increased phosphorylation or decreased ATPase in mitochondria from hypothyroid rats accounts for the decreases observed in the exchangeability and the exchange rates of internal adenine nucleotides.

\section{Effects of Temperature on $k_{\mathrm{T}}$}

Observations that the amount of ADP exchanged in $2 \mathrm{~min}$ at $0^{\circ} \mathrm{C}$ is below normal in $\mathrm{H}$ mitochondria, but is normal at $25^{\circ} \mathrm{C}$ (Table II), suggested further examination of the temperature dependence of translocation. The kinetics of translocation were mcasured over the temperature range 0 to $35^{\circ} \mathrm{C}$ as is detailed in the Methods section, comparing $\mathrm{N}$ and $\mathrm{H}$ mitochondria. Figure 5 shows reciprocal velocity-[ADP] plots obtained with $\mathrm{N}$ mitochondria at 25 to $35^{\circ} \mathrm{C}$, and with $\mathrm{H}$ mitochondria at $35^{\circ} \mathrm{C}$. The velocities measured at $20 \mu \mathrm{M}$ ADP fit the lines extrapolated from the slower, more reliable velocities at the lower [ADP], except for $\mathrm{N}$ mitochondria at $35^{\circ} \mathrm{C}$. Figure 6 shows no distinct trend of the apparent $K_{m}$ for $\mathrm{ADP}$ as temperature rises, except for a rise at $35^{\circ} \mathrm{C}$ with $\mathrm{N}$ mitochondria that may reflect the poor fit of the data to a line in Fig. 5.

The values for the $V$ of translocation at each temperature, together with those for $\mathrm{Ai}_{\mathrm{E}}$ (Fig. 2) were used to calculate $k_{\mathrm{T}}$ for $\mathrm{H}$ mitochondria. For $\mathrm{N}$ mitochondria, $\mathrm{Ai}_{\mathrm{E}}=$ $8.4 \mathrm{nmol} / \mathrm{mg}$ was assumed to be the ex-

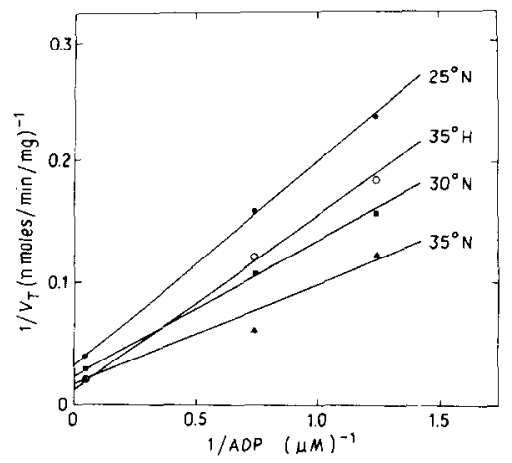

FIG. 5. Plots of reciprocal velocity versus [ADP] for liver mitochondria from normal $(\mathrm{N})$ or hypothyroid $(\mathrm{H})$ rats. Initial velocities were measured at the indicated temperatures, as in Fig. 3. changeable ATP + ADP level during the first $30 \mathrm{~s}$ of translocation (see Fig. 1) at each temperature. The Arrhenius plots for the normalized values of $k_{\mathrm{T}}$ are shown in Fig. 7. From 0 to $17^{\circ} \mathrm{C}, \log k_{\mathrm{T}}$ is linear with $\left[K^{\circ}\right]^{-1}$, with the energy of activation about $30 \%$ greater in the $\mathrm{H}$ mitochondria than in the normals. Above $17^{\circ} \mathrm{C}$, the $\log k_{\mathrm{T}}$ for $\mathrm{H}$ mitochondria continues to increase lin-

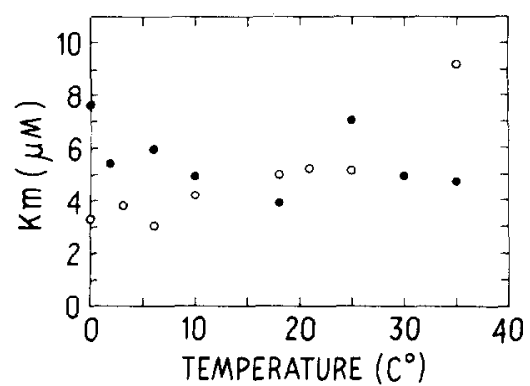

FIG. 6. The effect of temperature on the apparent $K_{m}$ for added ADP in the translocation assay, with liver mitochondria from normal (๑) or hypothyroid $(O)$ rats. Measurements of initial velocities were made at three ADP concentrations at each temperature, and $K_{m}$ was determined from plots of reciprocal velocity versus [ADP] $]^{-1}$ as in Fig. 4 and Methods.

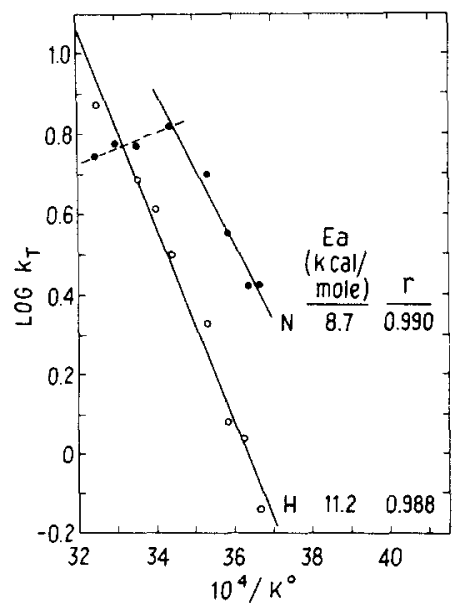

Fig. 7. The effect of temperature on the rate constant for specific ADP translocation, in liver mitochondria from normal $(\bullet, N)$ or hypothyroid $(\mathrm{O}, \mathrm{H})$ rats, shown as Arrhenius plots. The energies of activation $\left(E_{\mathrm{a}}\right)$ are calculated from the linear portions of each line by a least-squares method, and the fit of the data is indicated by the correlation coefficient $r$. The values for $k_{\mathrm{T}}$ were obtained from extrapolated values of the $V$ for translocation at each temperature as in Fig. 6, and as described in Methods. The broken line is discussed in the text. 
early, but $\log k_{\mathrm{T}}$ for $\mathrm{N}$ mitochondria decreases slightly. This decrease has not been reported in other studies $(4,12,18$, 26) and implies either an apparently negative $E_{\mathrm{a}}$, which is disconcerting, or more likely the intervention of a process different from thermal activation of the translocase system.

\section{DISCUSSION}

Mitochondria obtained from beef hearts and rat livers translocate ATP and ADP at a velocity that depends both on the content of endogenous exchangeable ATP + ADP and the activity of the translocator molecule (12). Liver mitochondria from normal and hypothyroid rats contain similar amounts of exchangeable ATP + ADP (Fig. 1) even though the latter have 60\% more total ATP + ADP (Table I). This compartmentation in $\mathrm{H}$ mitochondria resembles that in beef heart (15) and rat liver (27) mitochondria reported by some workers, although others have found complete exchangeability in such mitochondria (12), as we do (Fig. 1).

The apparent unreactivity of a portion of the endogenous nucleotides has been ascribed to a competition between the translocator and the phosphorylating system (3, 12). This explanation does not seem to account for the compartmentation in our $\mathrm{H}$ mitochondria. We measured translocation in the absence of $P_{1}$ and substrate to eliminate a significant amount of phosphorylation of ADP. Furthermore, blocking endogenous phosphorylation and ATPase action did not stimulate translocation (Table III).

Liver mitochondria from hypothyroid rats contain twice the normal amount of pyridine nucleotides $(28,29)$. In hypothyroidism, all the endogenous $\mathrm{NADP}^{+}$is reduced upon the addition of substrates, but an apparent compartmentation of endogenous NADP $(\mathrm{H})$ is produced by the addition of micromolar concentrations of $\mathrm{LT}_{4}(29)$. The nature of the binding of adenine nucleotides and pyridine nucleotides in normal mitochondria is not yet clear, so it is not possible to decide how the thyroid state affects nucleotide binding. In mitochondrial membranes the binding of ATP and
ADP inside the atractyloside barrier depends on $\left[\mathrm{Mg}^{2+}\right](30)$, and in blood platelet membranes ADP binding depends on $\left[\mathrm{Mg}^{2+}\right]$ and $\left[\mathrm{Ca}^{2+}\right]$ (31). Removal of a large portion of the $\mathrm{Mg}$ from normal mitochondria in a phosphate medium (32) also removes most of the endogenous ATP + ADP (12). The internal $\mathrm{Mg}$ and $\mathrm{Ca}$ contents of the liver mitochondria of hypothyroid rats are abnormal (32), but the changes from normal levels do not seem great enough to account for the excess nucleotides: $\mathrm{Mg}$ increases by $18 \%$, Ca decreases by $27 \%$, and their total of $50 \mathrm{ng}$ atoms $/ \mathrm{mg}$ of protein remains unchanged. The decreased binding of ATP and ADP by mitochondrial membranes treated relatively mildly with detergents (26) secms consistent with the involvement of proteins or lipids.

Our data on $v_{\mathrm{T}}$ and the values for $E_{\mathrm{a}}$ in liver mitochondria from normal rats do not agree well with those of other workers. The $v_{\mathrm{T}}$ at $0^{\circ} \mathrm{C}$ for external labeled ADP here is about three times greater than values obtained by a similar disc filtration method $(1,11)$ or by other methods $(12,18$, 26). The $v_{\mathrm{T}}$ at $0^{\circ} \mathrm{C}$ for mitochondria from hypothyroid rats is in the range observed by others for normals, so the filtration method used here can measure slow rates. Our measurements on normals show an $E_{\text {a }}$ value between 0 and $17^{\circ} \mathrm{C}$ that is 20 to $25 \%$ of the values reported below the transition temperature in measurements using centrifugal separations $(12,18)$. Above the transition temperature, others observe serve $E_{\mathrm{a}}$ 's of $21 \mathrm{kcal} / \mathrm{mol}$ (12) and $13 \mathrm{kcal} /$ mol (18), where we see an inhibition of $v_{\mathrm{T}}$ (Fig. 7). Together with this, the $v_{\mathrm{T}}$ at temperatures between 17 and $35^{\circ} \mathrm{C}$ reported here is about $70 \mathrm{nmol} / \mathrm{min} / \mathrm{mg}$, compared with a $v_{\mathrm{T}}$ of over $500 \mathrm{nmol} / \mathrm{min} / \mathrm{mg}$ at $30^{\circ} \mathrm{C}$ obtained with a rapid mixing and sampling apparatus (26). This last discrepancy, in view of a phosphorylation rate of about $200 \mathrm{nmol}$ of $\mathrm{ATP} / \mathrm{min} / \mathrm{mg}$ at $25^{\circ} \mathrm{C}$ that is completely inhibited by atractyloside and so presumably involves the translocator, makes it almost certain that above $17^{\circ} \mathrm{C}$, we are observing a mechanical and/ or thermal inactivation of the translocator during the disc filtration of normal mito- 
chondria, as has been implied by Klingenberg (26) for other studies. Our initial rate measurements do not seem at fault, for reasons described previously, and the high values for $v_{\mathrm{T}}$ below $17^{\circ} \mathrm{C}$ would seem to be ascribable to a variety of differences from procedures used by other investigators: our use of starved rats for a mitochondrial source, the strain of rats, their diet, their environmental temperature, and (at the risk of circular reasoning) their thyroid state.

Using the same filtration method, hypothyroid mitochondria respond differently to temperature changes than do normal mitochondria here or elsewhere. All agree upon the occurrence of a transition temperature between 0 and $30^{\circ} \mathrm{C}(4,12,17,26)$, and no such transition is observed with $\mathrm{H}$ mitochondria (Fig. 7). The 2-min uptake data (Table II), which do not involve the measurement of initial rates, show an anomalously greater uptake at $25^{\circ} \mathrm{C}$ in hypothyroids that is consistent with the Arrhenius plot. The filtration method seems to limit the maximal initial rate to about $70 \mathrm{nmol} / \mathrm{min} / \mathrm{mg}$ only when the mitochondrial lipids are in a fluid state above the transition temperature, and $\mathrm{H}$ mitochondria do not become "fluid" up to $35^{\circ} \mathrm{C}$. It is hoped that improved methodology will test these observations.

It appears then, even considering the limitations of the filtration technique, that the depressed translocating activity in hypothyroidism may be a result of changes in the amount or the properties of the protein translocator molecule. The first-order rate constant of translocation, $k_{\mathrm{T}}$, which reflects the properties, is decreased by $66 \%$ at $0^{\circ} \mathrm{C}$ in $\mathrm{H}$ mitochondria as compared to normals (Fig. 3). The decrease in both $V$ and $K_{m}$ (Fig. 4) suggests a change in the active form of the translocator; a decreased number of molecules of translocator would account only for the decrease in $V$. The specific binding of external ADP, which is a measure of the numbers of translocator sites (12), is not significantly altered in hypothyroidism (Table II). We detect no deficiencies of a mitochondrial polypeptide on SDS gel electrophoresis of inner membrane vesicles prepared from our hypothy- roid rat liver mitochondria $(6,33,34)$, at least of a magnitude large enough to account for the major decrease in translocation velocity. Although Baudry et al. (35) report a deficiency of a $54,000 M_{\mathrm{r}}$ protein, the translocator protein dimer would appear as monomers of a $M_{\mathrm{r}}$ of 29,000 (26).

There is reason to believe that the protein translocator molecule itself is not altered in hypothyroidism. Neither administration of hormones nor deficiencies of hormones lead to the synthesis of mutant proteins with a changed primary sequence of amino acids (36). Further, liver mitochondrial inner membranes obtained from hypothyroid rats contain no polypeptide components with abnormal electrophoretic mobilities $(6,33-35)$.

In contrast, evidence exists that the environment of the translocator protein in the inner mitochondrial membrane is changed in hypothyroidism. Changes in temperature affect the activity of the translocator quite differently in mitochondria from hypothyroid or normal rats (Table II, Fig. 7). The responses of membranedependent processes to changes in temperature depend mainly on the lipid environment of the protein carriers or enzymes $(13,37)$. The chemical composition of the polar and nonpolar portions of membrane phospholipids, and especially the degree of unsaturation, control the changes in rate constants with tempcrature $(38,39)$. Differences of less than $5 \%$ in the amount of unsaturated fatty acid have a marked effect on the freezing point of mixtures at the approximate composition of fatty acid in biological membrane lipids (40). In hypothyroidism, the total unsaturation of the phospholipid fatty acids in the rat liver mitochondrial inner membrane is significantly decreased, by $10 \%(33,34)$. This difference would account for the absence of a distinct transition temperature below $35^{\circ} \mathrm{C}$ in the $k_{\mathrm{T}}$ of translocation in $\mathrm{H}$ mitochondria (Fig. 7).

In hypothyroidism the abnormal composition of the inner membrane of liver mitochondria appears to alter the environment of the translocator molecule and of other processes as well. The Arrhenius profile of the phosphorylation of added ADP by digi- 
tonin-extracted inner membrane vesicles obtained from $\mathrm{H}$ mitochondria is linear from 0 to $30^{\circ} \mathrm{C}$, whereas that of normal vesicles shows a transition at $21^{\circ} \mathrm{C}(33,34)$. Analogous differences are seen in the temperature dependence of the nuclear glucose 6-phosphate phosphohydrolase activity (41). On the other hand, energy-dependent transhydrogenation of pyridine nucleotides at $30^{\circ} \mathrm{C}$ is markedly accelerated in sonicated vesicles prepared from $\mathrm{H}$ liver mitochondria, although the Arrhenius profile is unchanged $(6,42,43)$. These observations suggest that the protein molecules that mediate different membranedependent processes respond differently to the membrane lipid changes.

One injection of $\mathrm{LT}_{4}$ administered to a hypothyroid rat corrects the abnormal behavior of adenine nucleotide translocation in 3 days (Table II). The polyunsaturated fatty acid contents of the inner mitochondrial membrane are similarly corrected $(6$, $33,34)$. Such treatment is known to restore within 2 days several rates of synthesis that are depressed in hypothyroid liver cells: RNA and protein synthesis (24), and the synthesis of the phospholipids of the membranes of microsomes, mitochondria, and nuclei (25). The desaturation of essential polyenoic fatty acids $(34,44)$ is also accelerated by thyroid hormone in vitro. Each of these systems seems a possible target for hormone action to explain our observations.

\section{ACKNOWLEDGMENTS}

The expert technical assistance of Mrs. M. R. Dockrill is acknowledged.

\section{REFERENCES}

1. Portnay, G. I., McClendon, F. D., Bush, J. E., Braverman, L. E., and Babior, B. M. (1973) Biochem. Biophys. Res. Commun. 55, 17-21.

2. Klingenberg, M., and Pfaff, E. (1966) BBA Library 7, 180-201.

3. Heldt, H. W., and Pfaff, E. (1969) Eur. J. Biochem. 10, 494-500.

4. Vignais, P. V. (1976) Biochim. Biophys. Acta 456, 1-38.

5. Носн, F. L. (1975) Fed. Proc. 34, 314.

6. Hoch, F. L., Chen, Y.-D. I., Evans, T. C., Shaw, M. J., ANd NeYmark, M. A. (1976) in Thyroid Research, 1975. International Congress Series No. 378, pp. 347-351, Excerpta
Medica, Amsterdam.

7. Leblond, C. P., ANd Eartly, H. (1952) Endocrinology 51, 26-41.

8. Dimino, M. J., Kuras, R. A., McCleary, A. R., ANn Hoch, F. L. (1972) Arch. Biochem. Biophys. 150, 618-623.

9. Gornall, A. G., Bardawill, C. J., and David, M. W. (1949) J. Biol. Chem. 177, 751-766.

10. Weidemann, M. J., Erdelt, H., and KlingenBERG, M. (1970) Eur. J. Biochem. 16, 313-335.

11. Winkler, H H., Bygrave, F. L., And LehninGER, A. L. (1968) J. Biol. Chem. 243, 20-28.

12. Pfaff, E., Heldi, H. W., and Klingenberg, M. (1969) Eur. J. Biochem. 10, 484-493.

13. RaIson, J. K. (1973) J. Bioenergetics 4, 285-309.

14. Brierley, G., and Green, D. E. (1965) Proc. Nat. Acad. Sci. USA 53, 73-79.

15. Brierley, G., ANd O'Brien, R. L. (1965) J. Biol. Chem. 240, 4532-4539.

16. Greengard, P. (1965) in Methods of Enzymatic Analysis (Bergmeyer, H.-U., ed.), pp. 551558, Academic Press, New York.

17. Adam, H. (1965) in Methods of Enzymatic Analysis (Bergmeyer, H.-U., ed.), pp. 573-577, Academic Press, New York.

18. Duét, E. D., and Vignais, P. V. (1969) J. Biol. Chem. 244, 3920-3931.

19. Primack, M. P., AND Popovitch, J. R. (1974) 50th Meeting, American Thyroid Association, Inc., St. Louis, Mo.

20. Barker, S. B., Kiely, C. E., JR., Klitgaard, H. M., DrRks, H. B., Wang, S. C., AND WaWzoNEK, S. (1951) Endocrinology 48, 70-74.

21. Dillon, R. S., ANd Hoch, F. L. (1967) Biochem. Med. 1, 219-229.

22. Hoch, F. L. (1967) Proc. Nat. Acad. Sci. USA 58, 506-512.

23. TAtA, J. R. (1964) in Actions of Hormones on Molecular Processes (Litwack, G., and Kritchevsky, D., eds.), pp. 58-131, Wiley, New York.

24. TAtA, J. R. (1967) Biochem. J. 104, 1-16.

25. TATA, J. R. (1967) Nature (London) 213, 566-569.

26. KLingenberG, M. (1976) in The Enzymes of Biological Membranes (Martonosi, A., ed.), Vol. 3, pp. 383-438, Plenum Press, New York.

27. Out, T. A., AND Kemp, A., JR. (1974) Biochem. Soc. Trans. 2, 516-517.

28. KADENBACH, G. (1966) Biochem. Z. 344, 49-75.

29. Носн, F. L. (1976) J. Bioenerget. Biomembr. 8, 223-238.

30. Alexandre, A., Carignani, G., and Rossi, C. R. (1975) FEBS Lett. 52, 111-115.

31. Nachman, R. L., AND Ferris, B. (1974) J. Biol. Chem. 249, 704-710.

32. Magalhaes, M. C. D. (1975) Life Sci. 16, 10891094.

33. Chen, Y.-D. I. (1975) Thesis, University of Michigan.

34. Chen, Y.-D. I., And Hoch, F. L. (1976) Arch. 
Biochem. Biophys. 172, 741-744.

35. BAudry, M., Clot, J. P., ANd Michel, R. (1975) Biochimie 57, 77-83.

36. Frieden, E., ANd Lipner, H. (1971) Biochemical Endocrinology of the Vertebrates, Prentice Hall, N. J.

37. Fox, C. F. (1975) in MTP International Review of Science: Binchemistry, Series 1 (Fox, C. F., ed.), pp. 279-306, Butterworths, London.

38. Hinz, H. J., and Sturtevant, J. M. (1972) J. Biol. Chem. 247, 3697-3700.
39. Engleman, D. M., and Rothman, J. E. (1972) J. Biol. Chem. 247, 3694-3697.

40. Lyons, J. M., AND Asmundson, C. M. (1965) $J$. Amer. Oil Chem. Soc. 42, 1056-1058.

41. Shaw, M. J., AND Hoch, F. L. (1976) Life Sci. 19 , in press.

42. Evans, T. C. (1975) Fed. Proc. 34, 314.

43. Evans, T. C., and Hoch, F. L. (1976) Biochem. Biophys. Res. Commun. 69, 635-640.

44. FaAs, F. H., Carter, W. J., AND WynN, J, (1972) Endocrinology 91, 1481-1492. 